\title{
Role of modern imaging techniques for the in vivo diagnosis of lichen planus (Review)
}

\author{
SIMONA LAURA IANOȘI ${ }^{1}$, ANA MARIA FORSEA ${ }^{2}$, MIHAI LUPU $^{2}$, MIHAELA ADRIANA ILIE $^{3,4}$, \\ SABINA ZURAC ${ }^{5,6}$, DANIEL BODA ${ }^{4,7}$, GABRIEL IANOSI $^{8}$, DANIELA NEAGOE ${ }^{9}$, \\ CRISTINA TUTUNARU ${ }^{1}$, CRISTINA MARIA POPA ${ }^{1}$ and CONSTANTIN CARUNTU ${ }^{10,11}$
}

\author{
${ }^{1}$ Department of Dermatology, University of Medicine and Pharmacy of Craiova, Emergency County Hospital, 200349 Craiova; \\ ${ }^{2}$ Department of Dermatology, 'Carol Davila' University of Medicine and Pharmacy, Elias Emergency University Hospital, \\ 011461 Bucharest; ${ }^{3}$ Department of Biochemistry, 'Carol Davila' University of Medicine and Pharmacy; \\ ${ }^{4}$ Dermatology Research Laboratory, 'Carol Davila' University of Medicine and Pharmacy; ${ }^{5}$ Department of Pathology, \\ 'Carol Davila' University of Medicine and Pharmacy, 050474 Bucharest; ${ }^{6}$ Department of Pathology, \\ 'Colentina' University Hospital, 020125 Bucharest; ${ }^{7}$ Carol Medical Center, 010626 Bucharest; ${ }^{8}$ Department of Surgery, \\ University of Medicine and Pharmacy of Craiova, Military Hospital; ${ }^{9}$ Department of Internal Medicine, University of \\ Medicine and Pharmacy of Craiova, Emergency County Hospital, 200349 Craiova; ${ }^{10}$ Department of Physiology, \\ 'Carol Davila' University of Medicine and Pharmacy, 050474 Bucharest; ${ }^{11}$ Department of Dermatology, \\ 'Prof. N. Paulescu' National Institute of Diabetes, Nutrition and Metabolic Diseases, 011233 Bucharest, Romania
}

Received July 3, 2018; Accepted August 21, 2018

\section{DOI: $10.3892 / \mathrm{etm} .2018 .6974$}

\begin{abstract}
Lichen planus (LP) is a chronic inflammatory skin disease that can sometimes affect mucosal surfaces, with unknown pathogenesis, even though it appears to be an autoimmune disease. The diagnosis of lichen planus is usually based on histopathological examination of the lesions. Nowadays, the classical invasive diagnostic methods are replaced by modern non-invasive techniques. In this review, we present the main non-invasive imaging methods (dermoscopy, reflectance confocal microscopy, optical coherence tomography, ultrasound and diffuse reflection spectrophotometry) used in the diagnosis and therapeutic monitoring of lichen planus. Dermoscopy is a non-invasive method initially used for diagnosis of pigmented tumors but now is used also for inflammatory and infectious skin diseases. In lichen planus, the dermoscopy increases the accuracy of diagnosis, avoids skin biopsies commonly used and can be useful in the therapeutic monitoring by repeated investigation at different stages of treatment. Reflectance confocal microscopy (RCM) is a novel non-invasive imaging technique that is prevalently used for the diagnosis of skin tumors and inflammatory skin diseases. This
\end{abstract}

Correspondence to: Dr Daniel Boda, Dermatology Research Laboratory, 'Carol Davila' University of Medicine and Pharmacy, 8 Eroii Sanitari Avenue, 050474 Bucharest, Romania

E-mail: daniel.boda@yahoo.com

Key words: lichen planus, dermoscopy, reflectance confocal microscopy, opticalcoherence tomography, diffuse reflection spectrophotometry, ultrasound technology has been mostly employed for bedside, real-time microscopic evaluation of psoriasis, lichen planus, contact dermatitis, revealing specific confocal features to support clinical diagnosis and assist with patient management. Optical coherence tomography (OCT) is an emergent imaging technique, developed over the last decade, based on the interaction of the infrared radiation $(900-1,500 \mathrm{~nm})$ and the living tissues. A limited information exists on the benefits of OCT technology for the in vivo diagnosis of LP but could be a useful auxiliary tool in the in vivo differential diagnosis, especially in clinical equivocal settings like mucosal lesions, and in monitoring the response to treatment. Our review shows the possibility of using modern imaging techniques for the in vivo diagnosis and also for evaluation of the treatment response.

\section{Contents}

1. Introduction

2. Dermoscopy in LP

3. Reflectance confocal microscopy of LP

4. Optical coherence tomography of LP

5. Other techniques

6. Conclusion

\section{Introduction}

Lichen planus (LP), a chronic inflammatory dermatosis, usually affects middle aged people and both sexes with a minor female predominance (1-4). It frequently involves the skin, nails and scalp hair or mucous membranes (oral, esophageal, laryngeal, vulvovaginal and conjunctival mucosa) $(2,4,5)$. It often affects the flexor surface of the extremities. It has been shown that 
patients with oral LP also present cutaneous lesions in $16 \%$ of the cases, while $19 \%$ also present genital disease (6). The mean age is between 50-60 years for oral LP and between 40-45 years for cutaneous LP (7-9). The lesions are frequently bilateral and symmetric. The clinical presentation of lichen planus depends on the affected area. It is a disease with various clinical features. Based on the morphology and location of the lesions, it has different clinical subtypes, which include: papular (common), annular, actinic, atrophic, hypertrophic, vesiculobullous, follicular, linear, pigmentosus and pigmentosus-inversus (2). The classic skin lesions consists of polygonal papules that are flat and vary from erythematous to violaceus (2). The top of the lesion can have a thin or adherent scale (5). The pathognomonic findings are the lines called Wickham striae which are fine white lines that cross the plaque (5).

The precise cause of lichen planus is still unclear but studies suggest the interaction of genetic factors (in cutaneous lichen planus the presence of antigen HLA-DR1) with autoimmune mechanisms (association with autoimmune disorders such as alopecia areata and ulcerative colitis) or viral infections (the development rate of lichen planus is 2.5-4.5 higher in $\mathrm{HCV}$ seropositive patients) (10-13). Other factors include environmental factors, stress, anxiety, internal malignancies and dyslipidemia $(14,15)$. In lichen planus, $\mathrm{CD}^{+} \mathrm{T}$ lymphocytes have a major role as they are the most important components of the infiltrate that damages keratinocytes $(2,16,17)$.

Until now, in order to confirm the diagnosis of LP and start a correct treatment, biopsy and histopathological examination are required (2). The usual histopathological changes observed in lichen planus include orthokeratosis and compact hyperkeratosis, thickening of the granular layer, acanthosis, keratinocyte damage at the level of the basal layer, decreased population of epidermal melanocytes, inflammatory cells in the papillary dermis $(18,19)$.

Current trends for the diagnosis and especially the monitoring treatment response of certain skin and mucosal inflammatory diseases, such as psoriasis and acne, use modern non-invasive or minimally invasive techniques without the necessity of biopsy (20-23).

The aim of this study is to review the role of modern in vivo imaging techniques such as dermoscopy, reflectance confocal microscopy (RCM), optical coherence tomography (OCT), diffuse reflection spectrophotometry and ultrasound in the investigation of LP lesions and their correlation with classical histopathological features.

\section{Dermoscopy in LP}

Dermoscopy is a non-invasive method described for the first time by Braun in the 1990s and it was initially used for the diagnosis of pigmented skin tumors (24). Subsequently, the field of use of this investigation has expanded, and it is useful in a wide range of disorders such as benign or malignant, pigmented or non-pigmented skin tumors, as well as inflammatory or infectious skin diseases: psoriasis, lichen planus, sarcoidosis and scabies (25-27).

As stated before, the diagnosis of lichen planus is based on skin biopsy. Without minimizing the importance of the histopathological examination, dermoscopy has three important roles in LP. Firstly, it increases the accuracy of LP diagnosis, especially in the context in which this condition can embrace various clinical forms, often difficult to diagnose by clinical examination alone. Thus, differential diagnosis with syphilis, Darier's disease, acanthosis nigricans, lupus erythematous and psoriasis can be performed using a non-invasive technique (25). Secondly, using dermoscopy avoids skin biopsies commonly used in diagnosis of LP, but difficult to accept by the patient. Thirdly, dermoscopy can also be useful in the therapeutic monitoring of this condition by repeated investigations at different stages of treatment.

The dermoscopic semiology in LP includes mainly three elements: Wickham striae (WS), vascular patterns and pigment patterns, elements that vary depending on the clinical form of LP, the age of the disease and localization.

WS were first described by Wickham (28) 'as reticular streaks, dots or other varied configurations superimposed on a LP papule' being considered to date a pathognomonic sign for the diagnosis of LP (24). WS pathogenesis has caused numerous debates. Thus, Summerly and his collaborators considered that the presence of WS is due to a functional anomaly of keratinocytes, while Ryan and colleagues associated their presence with other causes and the diminution of the vascular network in the superficial dermis (24). In 1909, Darier correlated the formation of WS with hypergranulosis $(24,25)$. In the classical forms of LP, WS are commonly found, but there are other forms of LP in which they are absent (invisible WS) probably due to acute forms of the disease in which hypergranulosis has not yet been formed.The data from the literature show, on the one hand, a correlation between the presence or absence of WS and the histopathological changes specific to various clinical forms of LP, and on the other hand their presence correlates with the degree of disease activity or evolution under treatment $(26,27,29)$. WS are present in classical forms of LP, disappear after the treatment, and reappear after disease recurrences, being considered a marker of disease activity (26). From a dermoscopic point of view, we meet the classic reticular pattern of WS as white crossing lines (25). However, recent studies suggest introduction of new dermoscopic patterns for LP, such as the starry sky or leaf venation patterns (24). The starry sky pattern signifies clustered, follicular white dots of WS, possibly being a sequela of hypergranulosis $(29,30)$. The leaf venation pattern consists of side strips that branch out from the central WS venation and join together to mimic the snow crystals. Besides these dermoscopic aspects of WS, other patterns, such as linear, globular, perpendicular, veil-like or structureless, have also been described in the literature (29). Moreover, at the periphery of WS there were white, thin lines and blue-white veils probably as a consequence of the presence of melanophages in the deep dermis $(26,31)$. Also, sometimes yellowish or white non-structured patterns can be identified as associated with WS, probably due to dermal spongiosis and degeneration of the basal layer (32-34). In lichen planopilaris of the scalp, WS patterns are significant in recent lesions, while the veil-like structureless WS pattern is the main feature in this clinical form of LP (35).

The vascular patterns are a second feature of LP, the blood vessels being well visible through dermoscopy $(36,37)$. They appear in the form of red dots which represent the most important dermoscopic feature in the LP. In early lesions of actinic LP, peripheral homogeneous vascular patterns have been 


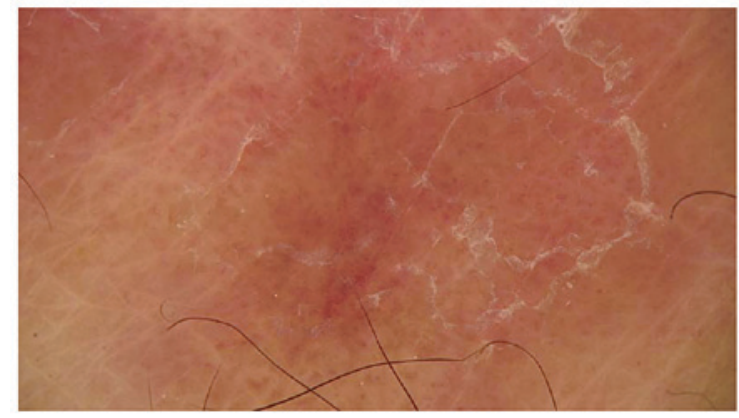

Figure 1. Dermoscopy image of a LP lesion (x30 magnification): Scaly, diffuse red dots on a brown background; WS absent. LP, Lichen planus; WS, Wickham striae.

encountered, this feature being significantly reduced or even absent after treatment (38). In conclusion, the most common dermoscopic aspects of WS have three characteristics: white, cross-linked and, as stated below, with red dots.

Pigment patterns are different depending on the form of LP. However, they show several important features $(32,39)$ such as: Are always present in certain clinical forms of LP, such as pigmented LP; different dermoscopic appearance can be observed in the same lesion; their dermoscopic appearance does not change after treatment.

Melanocyte proliferation is a dermoscopic marker $(34,39)$ expressed through pigmented dots, globules and diffuse hyperpigmentation, which are among the most common dermoscopic aspects in LP. Peppering pigment pattern shows the presence of melanophages in the superficial dermis. Moreover, crowding of melanophages around the blood vessels in the dermal papillae induces the dermoscopic pattern of pigment dots to papilla (24). Other pigment patterns encountered in LP lesions are perifollicular/annular/granular pattern, linear, reticular or cobblestone pattern, homogeneous cloud like pattern (Fig. 1).

\section{Reflectance confocal microscopy of LP}

Reflectance confocal microscopy (RCM) is a novel non-invasive imaging technique that is prevalently used in skin tumor diagnosis (40-44), also proving useful in clinical decision management (45-47). RCM provides 'optical skin biopsies', revealing microscopic-level changes across multiple skin layers with an en-face point of view (48). Various confocal criteria for melanocytic and non-melanocytic lesions have demonstrated both high sensitivity and specificity values, suggesting that in the future, the dissemination of RCM technique could, at least in selected cases, avoid unnecessary skin biopsies (49). Reflectance confocal microscopy represents, at the moment, the best possible bridge between dermoscopy and histology, giving clinicians the possibility of carrying out non-invasive, real-time, virtual skin biopsies. While in dermato-oncology RCM can deliver information regarding the nature of skin lesions and their malignant potential, in inflammatory skin diseases this technology has been mostly employed for bedside, real-time, microscopic evaluation of psoriasis (20,50-52), lichen planus $(18,48)$, contact dermatitis $(53)$, revealing specific confocal features to support clinical diagnosis and assist with patient management (54-57). Unfortunately, available data on confocal descriptors of inflammatory skin diseases focuses

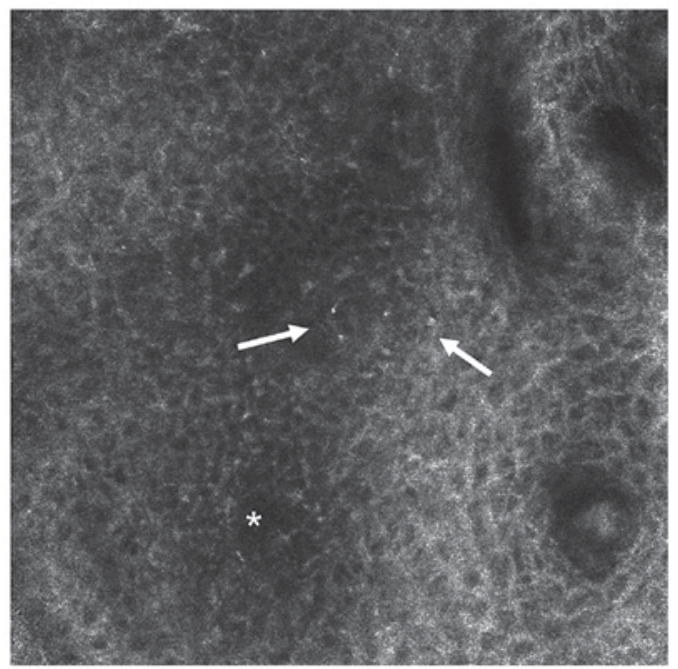

Figure 2. RCM image $(500 \times 500 \mu \mathrm{m})$ at the level of spinous layer showing dark areas (*) with large intercellular spaces between keratinocytes corresponding to spongiosis, partial loss of the normal honeycombed pattern corresponding to epidermal disorganization and inflammatory cells that appear as roundish bright structures (white arrows).

mainly on RCM-histology correlation and treatment follow-up, and very rarely on differential diagnosis $(51,58)$.

In LP, RCM examination reveals a well represented granular layer with large $(25-35 \mu \mathrm{m})$ polygonal cells containing a luminous grainy cytoplasm, corresponding to histological hypergranulosis (59-61). In normal skin, the difference between the granular and spinous layers is not readily distinguishable during RCM examination, due to the fact that granular cells are normally arranged in a thin layer. In LP however, due to hypergranulosis, the passage from granular to spinous layer is more easily observable. The spinous layer commonly shows localized bright areas with loss of the normal honeycomb pattern, and dark areas with thickened intercellular spaces corresponding to moderate spongiosis (Fig. 2). Numerous inflammatory infiltrates in the form of circular and polygonal bright elements can be observed throughout the epidermis (54). One characteristic confocal feature of LP is considered to be the presence of necrotic keratinocytes visualized as uniformly bright, polygonal cells, larger than surrounding keratinocytes (18) both in the spinous and basal layers, noticeable as Civatte bodies in histology (62). Some of the features noted above are part of probably the most common global pattern identified upon RCM examination of LP lesions, the interface dermatitis $(18,62,63)$.

The histological term 'interface dermatitis' refers to skin diseases in which an inflammatory process prevalently involves the dermo-epidermal junction (DEJ) showing the presence of focal or diffuse inflammatory infiltrates, injury or necrosis of basal keratinocytes, associated with vacuolar or lichenoid changes. Lichen planus, along with discoid lupus erythematosus (DLE), represent the prototypes for this group of cutaneous inflammatory diseases as their pathological processes both involve the DEJ. RCM has been employed in interface dermatitis and major and minor descriptors of this group of inflammatory diseases have already been characterized $(18,64)$. In accordance with optical microscopy findings, RCM has shown in LP lesions the presence of round, 


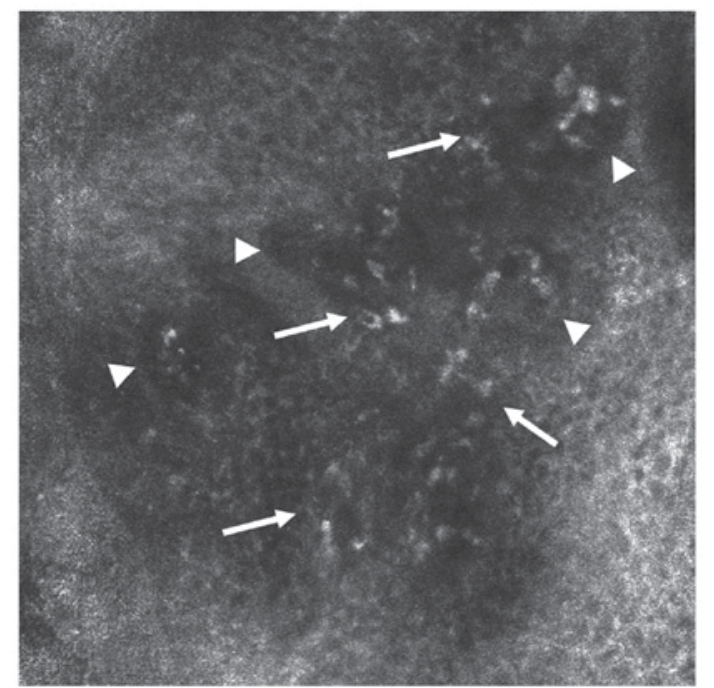

Figure 3. RCM image (500x500 $\mu \mathrm{m})$ at the level of the dermoepidermal junction showing bright inflammatory cells (white arrows) in the epidermis and within the non-edged and non-rimmed dermal papillae (white arrowheads).

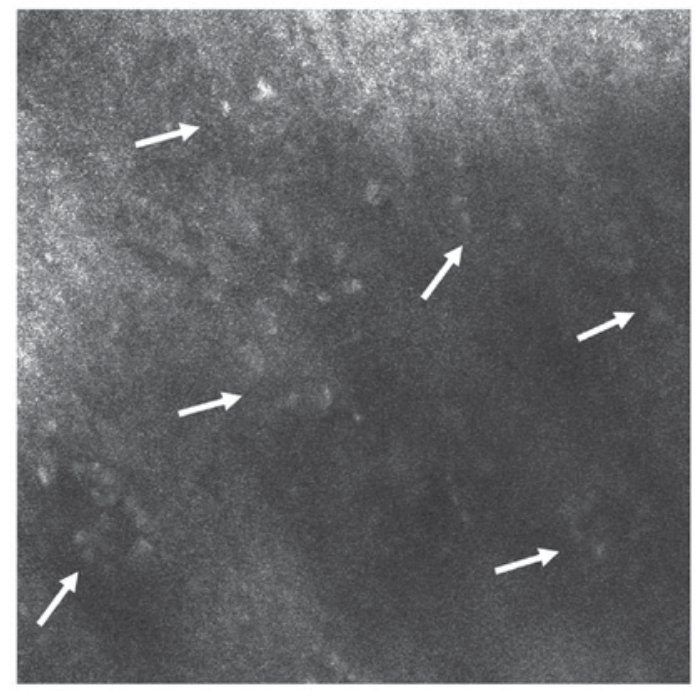

Figure 4. RCM image $(500 \times 500 \mu \mathrm{m})$ at the level of the papillary dermis showing numerous bright roundish or polygonal cells (white arrows) corresponding to the dermal inflammatory infiltrate. bright elements arranged in sheets, representing inflammatory infiltrates that obscure the DEJ (59). The dermal papillae (DP) are visible as dark, round areas. In interface dermatitis such as LP, RCM reveals a non-edged papillae pattern (Fig. 3).

Moving on from the shallow epidermal layers to the level of the upper dermis, a noteworthy finding is the presence of plump refractile structures, with shapes that vary from oval to stellar, representing melanophages. Round to polygonal, somewhat refractile cells, clearly smaller than melanophages, correlated to inflammatory cells, are also visible in the dermis (Fig. 4). Dilated dermal blood vessels appear as dark, canalicular structures, placed horizontally on confocal sections (65), in contrast to the vertical appearance of vessels depicted in other cutaneous inflammatory diseases such as psoriasis.

Summing up, nine common features of LP observable by RCM have been described: spongiosis (in various degrees), hypergranulosis, necrotic keratinocytes, single inflammatory cells, focal or diffuse inflammatory infiltrates, dilated blood vessels, interface dermatitis, dermal inflammatory infiltrates, melanophages in the upper dermis $(18,66,67)$.

Considering the aforementioned findings, it is without doubt that RCM can be of great aid in supporting the clinical diagnosis of LP. However, it is unable to distinguish between different leukocyte cell types thus limiting the interpretation of the inflammatory cell infiltrate, and has a limited depth of penetration of down to about $250 \mu \mathrm{m}$ below the skin surface (48) without the possibility of having a clear 'picture' of reticular dermis. Therefore, it is less helpful in the differential diagnosis of interface dermatitis (e.g., DLE vs. LP) (19) or in particular cases of lichen planus in which the diagnosis is hard to establish even after histopathological examination (68).

In spite of these limitations, the advantage of a non-invasive, real-time microscopic skin examination resides in the possibility of immediate clinical-microscopic correlations which clinicians can use in several clinical applications: major differential diagnosis, therapeutic follow-up examinations, and identification of the best possible site for a skin biopsy (19).
Larger studies demonstrating the diagnostic and differential diagnosis efficiency of RCM in the field of interface dermatitis are still needed.

\section{Optical coherence tomography of LP}

Optical coherence tomography (OCT) is an emergent imaging technique, developed over the last decade, based on the interaction of the infrared radiation (900-1500 nm) and the living tissues. It allows the non-invasive, in vivo visualization at high resolution of the micro-structural morphology of skin components (69). OCT is based on the principle of Michelson interferometry. A light source emits a light beam that is split into a reference beam and a probe beam, which is sent to the investigated tissue. The OCT device records the signals generated by the interference of the probe light back-scattered from the tissue with the reference beam. Measurement of the interference pattern allows determining the position of different absorbent or reflective tissues components, such as cell membranes or melanin pigment. The optical properties of the tissue and the central wavelength of the light beam determine the depth of penetration. Light absorption and scattering in the tissue sample should be minimized to allow maximal imaging depth, and this is best achieved for wavelengths in the window 700-1300 nm, with longer wavelengths performing better for deeper visualization (70).

The method was introduced in the medical practice in the field of ophthalmology in the 1990s, and expanded quickly to other specialties, from cardio-vascular surgery to gastroenterology, urology, neurology or gynecology (70). Its use in dermatology started to be explored in the 1990s, and currently several OCT systems have become commercially available for research and clinical practice for skin diseases. These various systems follow mainly two technological concepts, the time domain and frequency or spectral domain OCT (71). Wavelengths are used in the range between 930 and $1300 \mathrm{~nm}$ to achieve a visualization of superficial layers of the skin, as deep as $2 \mathrm{~mm}$, corresponding usually to the papillary dermis, 


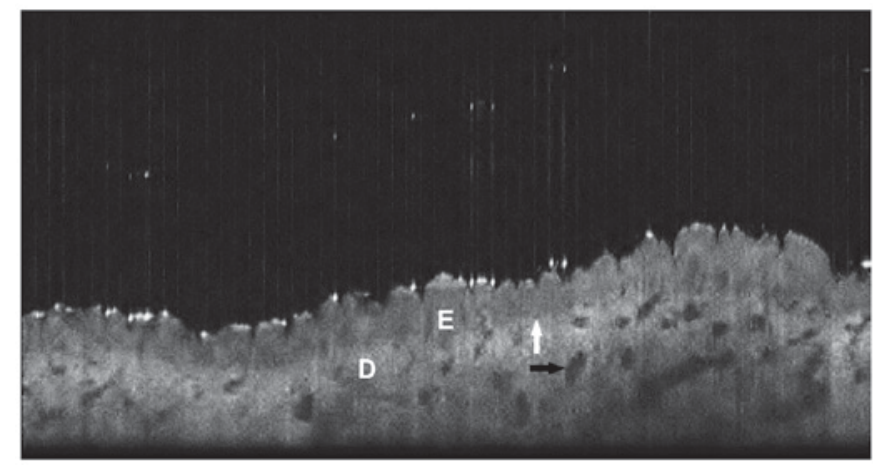

Figure 5. Normal skin. Cross sectional image obtained with Thorlabs OCP930SR Spectral Radar OCT device, equipped with a $930 \mathrm{~nm}$ ligh source. E, Epidermis; D, Dermis; white arrow, dermo-epidermal junction; black arrow, dermal blood vessels.

with a lateral resolution of 3-25 $\mu \mathrm{m}$ (72). The axial resolution varies between 3 and $12 \mu \mathrm{m}$, and the field of view between 1.6 to $10 \mathrm{~mm}$ diameter. The broadband light sources are preferred to improve axial resolution and depth visualization, and with longer wavelengths achieving deeper penetration but lower lateral resolution (71). Most systems provide in vivo, real-time, bi-dimensional cross-sectional images of the skin layers, comparable with low-magnification histopathological sections (Fig. 5). Some, like high-definition OCT (HD-OCT) system (Skintell; Agfa Healthcare, Mortsel, Belgium) delivers horizontal, en-face images, allowing a three dimensional visualization of skin structures.

OCT has shown promising results in the in vivo assessment of normal or diseased skin structure and properties, like the epidermal thickness, the architectural characteristics of skin appendages such as hair, glands and nails, the degree of skin fibrosis and the aspect of superficial dermal vessels $(71,72)$. Importantly, OCT allows monitoring of the dynamic changes of these characteristics in response to conservative treatments, without the need of invasive maneuvers $(73,74)$. The main body of research has been dedicated so far to the role of OCT in the pre-biopsy evaluation of skin tumors $(72,74,75)$, especially non-melanocytic neoplasms. Studies support the role of OCT in differentiating non-melanoma skin cancers from benign lesions and normal skin with sensitivities of $79-94 \%$ and specificities of $85-96 \%(72,76)$. Newer high-resolution HD-OCT systems are reported to allow for in vivo differentiating of histological subtypes of basal cell carcinoma, and grading of actinic keratoses $(77,78)$. OCT shows promising results in the pre-surgical estimation of lateral margins of tumors helping orientate the extent of surgery for complete resection $(72,79)$. Comparatively much less information is available on the value of OCT for the non-invasive assessment of inflammatory skin diseases. OCT can show the thickening of the epidermis and stratum corneum in psoriasis, the epidermic spongiosis in atopic or contact dermatitis and the dynamics of these alterations under topical treatment $(73,74,80,81)$. The changes at the dermo-epidermal junction (DEJ) such as the shape of the interline or the effacement of DEJ can be visualized. However, deeper inflammatory changes are hard to evaluate, especially in thicker skin, due to low penetration of this technique that is usually confined to the papillary dermis.

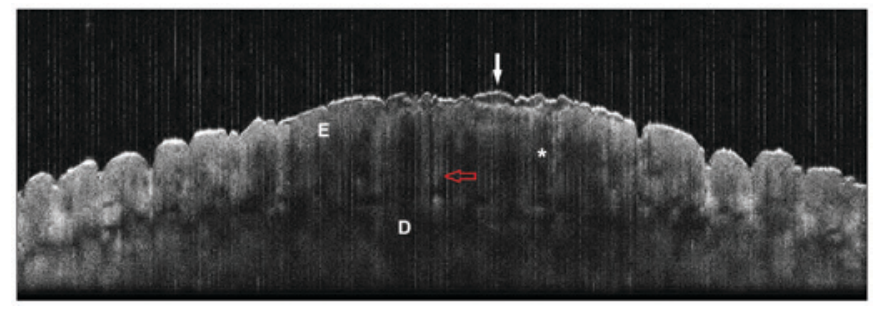

Figure 6. Lichen planus papule on a leg. Cross sectional image obtained with Thorlabs OCP930SR Spectral Radar OCT device, equipped with a $930 \mathrm{~nm}$ light source, field of view width $6 \mathrm{~mm}$. E, Epidermis; D, Dermis; white arrow, hyperkeratosis; red arrow, irregular acanthosis with saw-tooth appearance; *effacement of DEJ through band-like inflammatory infiltrate.

In this context very limited information exists on the benefits of OCT technology for the in vivo diagnosis of LP. The main study was performed by Boone et al who reported a series of 9 patients with histopathologically confirmed LP, investigated by HD-OCT (Skintell; Agfa Healthcare) (82). The time domain HD-OCT system used in their study provides $2 \mathrm{D}$ images of a $1.8 \times 1.5 \mathrm{~mm}^{2}$ field and a penetration depth of up to $0.57 \mathrm{~mm}$ at axial and lateral resolution of about $3 \mu \mathrm{m}$ each. This system natively collects stacked en-face images of the tissues, which can be reconstructed by proprietary algorithm into conventional b-mode, cross-sectional images. The authors reported to be able to visualize by HD-OCT important LP characteristics like irregular acanthosis with increased epidermal layer thickness, with saw-tooth appearance of the dermo-epidermal interline, focal hypergranulosis, and the typical interface inflammatory infiltrate, manifest as effacement of the DEJ interline (82). More subtle signs such as basal vacuolar degeneration visualized as total obliteration of the ring-like structures around the dermal papillae, or the presence of inflammatory and necrotic cells in the epidermis as bright spots were reported thanks to the availability of high-resolution en-face images. Importantly, these aspects allowed the authors to differentiate in vivo LP from more frequent inflammatory diseases with different infiltrate patterns like psoriasis or eczema (82). We observed comparable aspects on cross section using a conventional OCT system, at $930 \mathrm{~nm}$ wavelength (Thorlabs OCP930SR Spectral Radar; Thorlabs Inc., Newton, NJ, USA) (Fig. 6) (unpublished results). Schmitz et al, reported on one case where OCT was used to follow in vivo the dynamic changes in the lesions of palmo-plantar LP treated with UVA phototherapy (83).

Other authors reported on the use of OCT for the in vivo differentiation of oral mucosal lesions LP from malignant or premalignant oral cavity changes, or to monitor the evolution under treatment of recalcitrant oral LP (84). OCT can be used to identify architectural changes in the keratin cell layer, epithelial layer, basement membrane, lamina propria, and rete pegs of oral mucosa (85). Initial studies found that OCT could differentiate between oral squamous cell carcinoma versus all other oral pathologies, including LP with a sensitivity of 0.931 and specificity of $0.97(86,87)$. Later reports contested, however, the OCT ability to differentiate between different oral mucosal abnormalities (87).

These initial reports suggest that OCT could be an useful auxiliary tool in the in vivo differential diagnosis of LP, especially in clinical equivocal settings such as mucosal lesions, and 
in monitoring the response to treatment $(69,70)$. Confirmation of its use requires indication in larger series of patients. So far, the limits of the technology relate to the low depth penetration, which can make the visualization of DEJ difficult in areas with thicker skin, and the insufficient resolution of conventional OCT systems in order to allow identification of cellular changes. The higher resolution of the HD-OCT systems is counter-weighted by the lower penetration depth, of about $570 \mu \mathrm{m}$, and the small field of view. These features enhance the impact of the skin compression, patient's and examiner's movements during image acquisition, inducing higher variability of the results. Further drawbacks of the technique include the difficulties to visualize elevated lesions, the inter-observer variability and the longer learning curve, which demands solid knowledge of histopathology for the clinician who is evaluating the images $(26,71,72)$. Nonetheless, even if this technique's performance is not yet sufficient to replace histopathological examination for the nuanced diagnosis of LP and its variants, it has still the important advantages of a non-invasive investigation method, quick and well accepted by patients that can provide in real time helpful information to orientate and monitor the clinical approach. New developments, like image enhancement algorithms or systems that combine OCT with other imaging techniques such as Raman spectroscopy, fluorescence, Doppler and ultrasound, may further improve the diagnostic performance of OCT for the clinical research and practice of inflammatory skin diseases, while enhancing the cost-effectiveness and convenience of use (88).

\section{Other techniques}

Ultrasound is well known for over 30 years, being considered a non-invasive method useful in differential diagnosis of skin tumors, inflammatory or sclerotic skin diseases, or in evaluation of skin patch test and tuberculin test (88). Introduced in dermatological practice in the early 1970s, ultrasound used 1.5-5 MHz transducers with less satisfactory resolution because it allowed only visualization of deep structures: Large glands, veins and arteries, muscles and fatty tissue (89). Alexander and Miller in 1979 using a 15 MHz transducer were able to measure the thickness of the skin, but the first 15-20 MHz transducers, which appeared in the 1980s, allowed the visualization of dermis, subcutaneous tissue, arterioles and venules (89-92).

Nowadays it is necessary to use a transducer with a high frequency $(25-100 \mathrm{MHz})$ for the examination of superficial skin layers (epidermis, dermis) and mucous membranes with a thickness of $<2 \mathrm{~mm}(90,93,94)$. Examining the papules in LP, a hypoechogenic fusiform band, the maximum of the hypoechogenic zone corresponding to the maximum area of epidermal acanthosis and dermal inflammatory infiltrate, is observed (90).

Another non-invasive optic technique used to diagnose and monitor LP evolution is diffuse reflection spectrophotometry (DRS). Interaction between light and human tissue structures allows observation of the process of absorption and dispersion of light on biological tissues, with an essential role in obtaining spectral curves to give veracity to the diagnosis (95). Depending on the absorption power of the different skin structures, spectrophotometric images are born.
Regarding LP, DRS allows the detection of inflammatory cells such as localized T-lymphocytes in the epidermis $(95,96)$. DRS acts in the spectral range 400-450 nm, highlighting the presence of inflammatory cells in the LP, leading to the formation of a spectral reflection curve that helps the diagnosis and monitoring of this pathology (97).

\section{Conclusion}

LP is a chronic inflammatory skin condition affecting skin and or mucosal surfaces. There are several clinical types of LP that share similar histopathological features. Our review shows the possibility of using modern imaging techniques for the in vivo diagnosis and also for evaluation of the treatment response. In vivo techniques such dermoscopy, reflectance confocal microscopy, optical coherence tomography, diffuse reflection spectrophotometry and ultrasound, allow identification of specific aspects in LP lesions and to correlate them with histological findings. Moreover, combining these techniques may improve the accuracy of the diagnosis.

\section{Acknowledgements}

Not applicable.

\section{Funding}

This work was partially supported by a grant of the Romanian Ministry of Research and Innovation, CCCDI-UEFISCDI (project no. 61PCCDI/2018 PN-III-P1-1.2-PCCDI-2017-0341), within PNCDI-III.

\section{Availability of data and materials}

Not applicable.

\section{Authors' contributions}

SLI, AMF, ML, MAI, SZ, BD, GI, DN, CT, CMP and CC contributed to the acquisition and design, analysis and systematization of data, manuscript drafting and critical revision of manuscript for important intellectual content. All authors read and approved the final version of manuscript.

\section{Ethics approval and consent to participate}

Not applicable.

\section{Patient consent for publication}

Not applicable.

\section{Competing interests}

The authors declare that they have no competing interests.

\section{References}

1. Le Cleach L and Chosidow O: Clinical practice. Lichen planus. N Engl J Med 366: 723-732, 2012. 
2. Gorouhi F, Davari P and Fazel N: Cutaneous and mucosal lichen planus: A comprehensive review of clinical subtypes, risk factors, diagnosis, and prognosis. ScientificWorldJournal 2014 742826, 2014.

3. Fazel N: Cutaneous lichen planus: A systematic review of treatments. J Dermatolog Treat 26: 280-283, 2015.

4. Arora SK, Chhabra S, Saikia UN, Dogra S and Minz RW: Lichen planus: A clinical and immuno-histological analysis. Indian J Dermatol 59: 257-261, 2014.

5. Friedman P, Sabban EC, Marcucci C, Peralta R and Cabo H: Dermoscopic findings in different clinical variants of lichen planus. Is dermoscopy useful? Dermatol Pract Concept 5: 51-55, 2015.

6. Eisen D: The clinical features, malignant potential, and systemic associations of oral lichen planus: A study of 723 patients. J Am Acad Dermatol 46: 207-214, 2002.

7. Carbone M, Arduino PG, Carrozzo M, Gandolfo S, Argiolas MR, Bertolusso G, Conrotto D, Pentenero $M$ and Broccoletti R: Course of oral lichen planus: A retrospective study of 808 northern Italian patients. Oral Dis 15: 235-243, 2009.

8. Bermejo-Fenoll A, Sánchez-Siles M, López-Jornet P, Camacho-Alonso F and Salazar-Sánchez N: A retrospective clinicopathological study of 550 patients with oral lichen planus in south-eastern Spain. J Oral Pathol Med 39: 491-496, 2010.

9. Irvine C, Irvine F and Champion RH: Long-term follow-up of lichen planus. Acta Derm Venereol 71: 242-244, 1991.

10. Sugerman PB, Savage NW, Walsh LJ, Zhao ZZ, Zhou XJ, Khan A, Seymour GJ and Bigby M: The pathogenesis of ora lichen planus. Crit Rev Oral Biol Med 13: 350-365, 2002.

11. Epidemiological evidence of the association between lichen planus and two immune-related diseases. Alopecia areata and ulcerative colitis. Gruppo Italiano Studi Epidemiologici in Dermatologia. Arch Dermatol 127: 688-691, 1991.

12. Lodi G, Pellicano R and Carrozzo M: Hepatitis C virus infection and lichen planus: A systematic review with meta-analysis. Oral Dis 16: 601-612, 2010.

13. Shengyuan L, Songpo Y, Wen W, Wenjing T, Haitao Z, Binyou W and Hepatitis C: Hepatitis $C$ virus and lichen planus: A reciprocal association determined by a meta-analysis. Arch Dermatol 145: 1040-1047, 2009.

14. Girardi C, Luz C, Cherubini K, de Figueiredo MA, Nunes ML and Salum FG: Salivary cortisol and dehydroepiandrosterone (DHEA) levels, psychological factors in patients with oral lichen planus. Arch Oral Biol 56: 864-868, 2011.

15. Constantin C, Corina G, Ana C, Adriana D and Daniel B: The role of stress in skin diseases. Intern Med 8: 73-84, 2011.

16. Iijima W, Ohtani H, Nakayama T, Sugawara Y, Sato E, Nagura $\mathrm{H}$, Yoshie $\mathrm{O}$ and Sasano T: Infiltrating $\mathrm{CD} 8^{+} \mathrm{T}$ cells in oral lichen planus predominantly express CCR5 and CXCR3 and carry respective chemokine ligands RANTES/CCL5 and IP-10/CXCL10 in their cytolytic granules: A potential self-recruiting mechanism. Am J Pathol 163: 261-268, 2003.

17. Sharma A, Białynicki-Birula R, Schwartz RA and Janniger CK: Lichen planus: An update and review. Cutis 90: 17-23, 2012.

18. Moscarella E, González S, Agozzino M, Sánchez-Mateos JL, Panetta C, Contaldo M and Ardigò M: Pilot study on reflectance confocal microscopy imaging of lichen planus: A real-time, non-invasive aid for clinical diagnosis. J Eur Acad Dermatol Venereol 26: 1258-1265, 2012

19. Agozzino M, Gonzalez S and Ardigò M: Reflectance confocal microscopy for inflammatory skin diseases. Actas Dermosifiliogr 107: 631-639, 2016.

20. Batani A, Brănișteanu DE, Ilie MA, Boda D, Ianosi S, Ianosi G and Caruntu C: Assessment of dermal papillary and microvascular parameters in psoriasis vulgaris using in vivo reflectance confocal microscopy. Exp Ther Med 15: 1241-1246, 2018.

21. Manfredini M, Greco M, Farnetani F, Ciardo S, De Carvalho N, Mandel VD, Starace M and Pellacani G: Acne: Morphologic and vascular study of lesions and surrounding skin by means of optical coherence tomography. J Eur Acad Dermatol Venereol 31: 1541-1546, 2017.

22. Ianosi S, Neagoe D, Calbureanu M and Ianosi G: Investigator-blind, placebo-controlled, randomized comparative study on combined vacuum and intense pulsed light versus intense pulsed light devices in both comedonal and papulopustular acne. J Cosmet Laser Ther 15: 248-254, 2013.

23. Caruntu C, Boda D, Dumitrascu G, Constantin C and Neagu M: Proteomics focusing on immune markers in psoriatic arthritis. Biomarkers Med 9: 513-528, 2015.

24. Tan C, Min ZS, Xue Y and Zhu WY: Spectrum of dermoscopic patterns in lichen planus: A case series from China. J Cutan Med Surg 18: 28-32, 2014.
25. Vázquez-López F, Gómez-Díez S, Sánchez J and Pérez-Oliva N: Dermoscopy of active lichen planus. Arch Dermatol 143: 1092, 2007.

26. Zalaudek I and Argenziano G: Dermoscopy subpatterns of inflammatory skin disorders. Arch Dermatol 142: 808, 2006.

27. Lallas A, Kyrgidis A, Tzellos TG, Apalla Z, Karakyriou E, Karatolias A, Lefaki I, Sotiriou E, Ioannides D, Argenziano G, et al: Accuracy of dermoscopic criteria for the diagnosis of psoriasis, dermatitis, lichen planus and pityriasis rosea. Br J Dermatol 166: 1198-1205, 2012.

28. Wickham L: Sur un signe pathognomonique du lichen de Wilson (lichen plan) Stries et ponctuations grisatres. Ann Dermatol Syph 6: 517-520, 1895.

29. Vázquez-López F, Manjón-Haces JA, Maldonado-Seral C, Raya-Aguado C, Pérez-Oliva N and Marghoob AA: Dermoscopic features of plaque psoriasis and lichen planus: New observations. Dermatology 207: 151-156, 2003.

30. Güngör Ş, Topal IO and Göncü EK: Dermoscopic patterns in active and regressive lichen planus and lichen planus variants: A morphological study. Dermatol Pract Concept 5: 45-53, 2015.

31. Vazquez-Lopez F, Palacios-Garcia L, Gomez-Diez S and Argenziano G: Dermoscopy for discriminating between lichenoid sarcoidosis and lichen planus. Arch Dermatol 147: 1130-1130, 2011

32. Güngör Ş, Topal IO, Erdogan Ş and Özcan D: Classical lichen planus and lichen planus pigmentosus inversus overlap with dermoscopic features. Our Dermatol Online 5: 42-44, 2014

33. Vázquez-López F, Vidal AM and Zalaudek I: Dermoscopic subpatterns of ashy dermatosis related to lichen planus. Arch Dermatol 146: 110, 2010.

34. Vázquez-López F, Maldonado-Seral C, López-Escobar M and Pérez-Oliva N: Dermoscopy of pigmented lichen planus lesions. Clin Exp Dermatol 28: 554-555, 2003.

35. Summerly R and Jones EW: The microarchitecture of Wickham's striae. Trans St Johns Hosp Dermatol Soc 50: 157-161, 1964.

36. Ryan TJ: Lichen planus, Whickham's striae and blood vessels. Br J Dermatol 85: 497-498, 1971

37. Liebman TN, Rabinovitz HS, Dusza SW and Marghoob AA: White shiny structures: dermoscopic features revealed under polarized light. J Eur Acad Dermatol Venereol 26: 1493-1497, 2012.

38. Vázquez-López F, Alvarez-Cuesta C, Hidalgo-García Y and Pérez-Oliva N: The handheld dermatoscope improves the recognition of Wickham striae and capillaries in Lichen planus lesions. Arch Dermatol 137: 1376-1376, 2001.

39. Soyer HP, Argenziano G, Chimenti S and Ruocco V: Dermoscopy of pigmented skin lesions: Eur J Dermatol 11: 270-276, 2001.

40. Diaconeasa A, Boda D, Neagu M, Constantin C, Căruntu C, Vlădău L and Guțu D: The role of confocal microscopy in the dermato-oncology practice. J Med Life 4: 63-74, 2011.

41. Ghita MA, Caruntu C, Rosca AE, Kaleshi H, Caruntu A Moraru L, Docea AO, Zurac S, Boda D, Neagu M, et al: Reflectance confocal microscopy and dermoscopy for in vivo, non-invasive skin imaging of superficial basal cell carcinoma. Oncol Lett 11: 3019-3024, 2016.

42. Căruntu C, Boda D, Guţu DE and Căruntu A: In vivo reflectance confocal microscopy of basal cell carcinoma with cystic degeneration. Rom J Morphol Embryol 55: 1437-1441, 2014.

43. Lupu M, Caruntu C, Solomon I, Popa A, Lisievici C, Draghici C, Papagheorghe L, Voiculescu VM and Giurcaneanu C: The use of in vivo reflectance confocal microscopy and dermoscopy in the preoperative determination of basal cell carcinoma histopathological subtypes. DermatoVenerol 62: 7-13, 2017.

44. Lupu M, Caruntu A, Caruntu C, Boda D, Moraru L, Voiculescu V and Bastian A: Non-invasive imaging of actinic cheilitis and squamous cell carcinoma of the lip. Mol Clin Oncol 8: 640-646, 2018.

45. Langley RGB, Rajadhyaksha M, Dwyer PJ, Sober AJ, Flotte TJ and Anderson RR: Confocal scanning laser microscopy of benign and malignant melanocytic skin lesions in vivo. J Am Acad Dermatol 45: 365-376, 2001.

46. González S: Confocal reflectance microscopy in dermatology: Promise and reality of non-invasive diagnosis and monitoring. Actas Dermosifiliogr 100 (Suppl 2): 59-69, 2009.

47. Guida S, Longo C, Casari A, Ciardo S, Manfredini M, Reggiani C, Pellacani G and Farnetani F: Update on the use of confocal microscopy in melanoma and non-melanoma skin cancer. G Ital Dermatol Venereol 150: 547-563, 2015. 
48. Alessi SS, Nico MMS, Fernandes JD and Lourenco SV: Reflectance confocal microscopy as a new tool in the in vivo evaluation of desquamative gingivitis: Patterns in mucous membrane pemphigoid, pemphigus vulgaris and oral lichen planus. Br J Dermatol 168: 257-264, 2013

49. Farnetani F, Scope A, Braun RP, Gonzalez S, Guitera P, Malvehy J, Manfredini M, Marghoob AA, Moscarella E, Oliviero M, et al: Skin cancer diagnosis with reflectance confocal microscopy: Reproducibility of feature recognition and accuracy of diagnosis JAMA Dermatol 151: 1075-1080, 2015.

50. Căruntu C, Boda D, Căruntu A, Rotaru M, Baderca F and Zurac S In vivo imaging techniques for psoriatic lesions. Rom J Morphol Embryol 55: 1191-1196, 2014.

51. Agozzino M, Berardesca E, Donadio C, Franceschini C, de Felice CM, Cavallotti C, Sperduti I and Ardigò M: Reflectance confocal microscopy features of seborrheic dermatitis for plaque psoriasis differentiation. Dermatology 229: 215-221, 2014.

52. Ardigo M, Cota C, Berardesca E and González S: Concordance between in vivo reflectance confocal microscopy and histology in the evaluation of plaque psoriasis. J Eur Acad Dermatol Venereol 23: 660-667, 2009.

53. González S, González E, White WM, Rajadhyaksha M and Anderson RR: Allergic contact dermatitis: Correlation of in vivo confocal imaging to routine histology. J Am Acad Dermatol 40: 708-713, 1999.

54. Białek-Galas K, Wielowieyska-Szybińska D, Dyduch G and Wojas-Pelc A: The use of reflectance confocal microscopy in selected inflammatory skin diseases. Pol J Pathol 66: 103-108, 2015.

55. Başaran YK, Gürel MS, Erdemir AT, Turan E, Yurt N and Bağci IS: Evaluation of the response to treatment of psoriasis vulgaris with reflectance confocal microscopy. Skin Res Technol 21: 18-24, 2015.

56. Căruntu C and Boda D: Evaluation through in vivo reflectance confocal microscopy of the cutaneous neurogenic inflammatory reaction induced by capsaicin in human subjects. J Biomed Opt 17: 085003, 2012.

57. Ghiță MA, Căruntu C, Rosca AE, Căruntu A, Moraru L, Constantin C, Neagu M and Boda D: Real-time investigation of skin blood flow changes induced by topical capsaicin. Acta Dermatovenerol Croat 25: 223-227, 2017

58. Hoogedoorn L, Peppelman M, van de Kerkhof PC, van Erp PE and Gerritsen MJ: The value of in vivo reflectance confocal microscopy in the diagnosis and monitoring of inflammatory and infectious skin diseases: A systematic review. Br J Dermatol 172: 1222-1248, 2015

59. Rajadhyaksha M, González S, Zavislan JM, Anderson RR and Webb RH: In vivo confocal scanning laser microscopy of human skin II: Advances in instrumentation and comparison with histology. J Invest Dermatol 113: 293-303, 1999.

60. Hofmann-Wellenhof R, Pellacani G, Malvehy J and Soyer HP (eds). Interface dermatitis. In: Reflectance Confocal Microscopy for Skin Diseases. Springer, Berlin, pp392-400, 2012.

61. Bağcı IS, Gürel MS, Aksu AEK, Erdemir AT, Yüksel Eİ and Başaran YK: Reflectance confocal microscopic evaluation of nonmelanocytic lip lesions. Lasers Med Sci 32: 1497-1506, 2017

62. Longo C, Zalaudek I, Argenziano G and Pellacani G: New directions in dermatopathology: In vivo confocal microscopy in clinical practice. Dermatol Clin 30: 799-814, viii, 2012

63. Contaldo M, Agozzino M, Moscarella E, Esposito S, Serpico R and Ardigò M: In vivo characterization of healthy oral mucosa by reflectance confocal microscopy: A translational research for optical biopsy. Ultrastruct Pathol 37: 151-158, 2013.

64. Ardigò M, Maliszewski I, Cota C, Scope A, Sacerdoti G, Gonzalez S and Berardesca E: Preliminary evaluation of in vivo reflectance confocal microscopy features of discoid lupus erythematosus. Br J Dermatol 156: 1196-1203, 2007.

65. Kelloff GJ, Sullivan DC, Baker H, Clarke LP, Nordstrom R, Tatum JL, Dorfman GS, Jacobs P, Berg CD, Pomper MG, et al; Workshop Program Committee: Workshop on imaging science development for cancer prevention and preemption. Cancer Biomark 3: 1-33, 2007.

66. Calzavara-Pinton $\mathrm{P}$, Longo $\mathrm{C}$, Venturini $\mathrm{M}$, Sala $\mathrm{R}$ and Pellacani G: Reflectance confocal microscopy for in vivo skin imaging. Photochem Photobiol 84: 1421-1430, 2008.

67. Ardigo M, Donadio $C$, Franceschini C, Catricalà $C$ and Agozzino M: Interest of reflectance confocal microscopy for inflammatory oral mucosal diseases. J Eur Acad Dermatol Venereol 29: 1850-1853, 2015.
68. Baderca F, Lighezan R, Alexa A, Zăhoi D, Raica M, Izvernariu D and Ardelean L: Atypical variant of lichen planus mimicking normal skin histology. Rom J Morphol Embryol 52: 1355-1360, 2011.

69. Serup J, Jemec GBE and Grove GL (eds): Optical coherence tomography in dermatology. In: Handbook of Non-Invasive Methods and the Skin. 2nd edition. CRC Press, Boca Raton, FL, 2006.

70. Gambichler T, Jaedicke V and Terras S: Optical coherence tomography in dermatology: Technical and clinical aspects. Arch Dermatol Res 303: 457-473, 2011.

71. Sattler E, Kästle R and Welzel J: Optical coherence tomography in dermatology. J Biomed Opt 18: 061224, 2013.

72. Gambichler T, Pljakic A and Schmitz L: Recent advances in clinical application of optical coherence tomography of human skin. Clin Cosmet Investig Dermatol 8: 345-354, 2015.

73. Jung S, Lademann J, Darvin ME, Richter C, Pedersen CB, Richter H, Schanzer S, Kottner J, Blume-Peytavi U and Røpke MA: In vivo characterization of structural changes after topical application of glucocorticoids in healthy human skin. J Biomed Opt 22: 76018, 2017.

74. Levine A, Wang K and Markowitz O: Optical coherence tomography in the diagnosis of skin cancer. Dermatol Clin 35: 465-488, 2017

75. Popescu I, Carstea E, Turcu G, Giurcaneanu C and Forsea A Multimodal optospectral investigation of melanocytic skin lesions: A correlation study using optical coherence tomography and dermoscopy. Rom Rep Phys 66: 672-682, 2014.

76. Mogensen M, Joergensen TM, Nürnberg BM, Morsy HA, Thomsen JB, Thrane L and Jemec GB: Assessment of optical coherence tomography imaging in the diagnosis of non-melanoma skin cancer and benign lesions versus normal skin. Dermatol Surg 35: 965-972, 2009.

77. Boone MALM, Suppa M, Pellacani G, Marneffe A, Miyamoto M, Alarcon I, Ruini C, Hofmann-Wellenhof R, Malvehy J, Jemec GBE, et al: High-definition optical coherence tomography algorithm for discrimination of basal cell carcinoma from clinical BCC imitators and differentiation between common subtypes. J Eur Acad Dermatol Venereol 29: 1771-1780, 2015

78. Boone MALM, Suppa M, Marneffe A, Miyamoto M, Jemec GBE and Del Marmol V: A new algorithm for the discrimination of actinic keratosis from normal skin and squamous cell carcinoma based on in vivo analysis of optical properties by high-definition optical coherence tomography. J Eur Acad Dermatol Venereol 30: 1714-1725, 2016

79. Wang KX, Meekings A, Fluhr JW, McKenzie G, Lee DA, Fisher J, Markowitz O and Siegel DM: Optical coherence tomography-based optimization of mohs micrographic surgery of Basal cell carcinoma: A pilot study. Dermatol Surg 39: 627-633, 2013.

80. Olsen J, Themstrup L and Jemec GB: Optical coherence tomography in dermatology. G Ital Dermatol Venereol 150: 603-615, 2015.

81. Forsea A-M, Carstea EM, Ghervase L, Giurcaneanu C and Pavelescu G: Clinical application of optical coherence tomography for the imaging of non-melanocytic cutaneous tumors: A pilot multi-modal study. J Med Life 3: 381-389, 2010.

82. Boone M, Norrenberg S, Jemec G and Del Marmol V: High-definition optical coherence tomography: adapted algorithmic method for pattern analysis of inflammatory skin diseases: a pilot study. Arch Dermatol Res 305: 283-297, 2013

83. Schmitz L, Gambichler T, Zerbinati N and Dirschka T: Optical coherence tomography of palmoplantar lichen planus and ultraviolet A1 laser treatment: A case report. J Dtsch Dermatol Ges 12: e9-e10, 2014.

84. Fomina IuV, Gladkova ND, Leont'ev VK, Urutina MN, Gazhva SI, Snopova LB, Gelikonov VM and Kamenskiǔ VA: Optical coherence tomography in the evaluation of the oral cavity mucosa. Part II. Benign and malignant diseases. Stomatologiia (Mosk) 83: 25-32, 2004 (In Russian).

85. Hamdoon Z, Jerjes W, Al-Delayme R, McKenzie G, Jay A and Hopper C: Structural validation of oral mucosal tissue using optical coherence tomography. Head Neck Oncol 4: 29, 2012.

86. Wilder-Smith P, Lee K, Guo S, Zhang J, Osann K, Chen Z and Messadi D: In vivo diagnosis of oral dysplasia and malignancy using optical coherence tomography: Preliminary studies in 50 patients. Lasers Surg Med 41: 353-357, 2009.

87. Bhatia N, Lalla Y, Vu AN and Farah CS: Advances in optical adjunctive AIDS for visualisation and detection of oral malignant and potentially malignant lesions. Int J Dent 2013: 194029, 2013. 
88. Adabi S, Turani Z, Fatemizadeh E, Clayton A and Nasiriavanaki M: Optical coherence tomography technology and quality improvement methods for optical coherence Tomography images of skin: A short review. Biomed Eng Comput Biol 8: $1179597217713475,2017$.

89. Alexander $\mathrm{H}$ and Miller DL: Determining skin thickness with pulsed ultra sound. J Invest Dermatol 72: 17-19, 1979.

90. El Gammal S, El Gammal C, Kaspar K, Pieck C, Altmeyer P, Vogt M and Ermert H: Sonography of the skin at $100 \mathrm{MHz}$ enables in vivo visualization of stratum corneum and viable epidermis in palmar skin and psoriatic plaques. J Invest Dermatol 113: 821-829, 1999.

91. El Gammal S, Auer T, Hoffmann K, Altmeyer P, Passmann C and Ermert $\mathrm{H}$ : Grundlagen, anwendungsgebiete und grenzen des hochfrequenten $(20-50 \mathrm{MHz})$ ultraschalls in der dermatologie. Zbl Haut 162: 817-838, 1993 (In German).

92. El-Gammal S, Auer T, Hoffmann K, Matthes $U$ and Altmeyer P: Möglichkeiten und Grenzen der hochauflösenden (20 und $50 \mathrm{MHz}$ ) Sonographie in der Dermatologie. Aktuelle Derm 18: 197-208, 1992 (In German).

93. Seidenari S and Di Nardo A: B scanning evaluation of irritant reactions with binary transformation and image analysis. Acta Derm Venereol Suppl (Stockh) 175: 9-13, 1992.
94. Seidenari S: High-frequency sonography combined with image analysis: A noninvasive objective method for skin evaluation and description. Clin Dermatol 13: 349-359, 1995.

95. Jayanthi JL, Nisha GU, Manju S, Philip EK, Jeemon P, Baiju KV, Beena VT and Subhash N: Diffuse reflectance spectroscopy: Diagnostic accuracy of a non-invasive screening technique for early detection of malignant changes in the oral cavity. BMJ Open 1: e000071, 2011.

96. Messadi DV, Younai FS, Liu HH, Guo G and Wang CY: The clinical effectiveness of reflectance optical spectroscopy for the in vivo diagnosis of oral lesions. Int J Oral Sci 6: 162-167, 2014.

97. Gupta S and Jawanda MK: Oral Lichen Planus: An update on etiology, pathogenesis, clinical presentation, diagnosis and management. Indian J Dermatol 60: 222-229, 2015.

(i) (9) This work is licensed under a Creative Commons Attribution-NonCommercial-NoDerivatives 4.0 International (CC BY-NC-ND 4.0) License. 